\title{
EL RITMO DE LA SOCIABILIDAD FESTIVA EN LAS FALLAS DE VALENCIA ${ }^{1}$
}

\author{
XAVIER COSTA GRANELL \\ Universidad de Valencia \\ PALABRAS CLAVE ADICIONALES \\ ADDITIONAL KEYWORDS \\ Sociabilidad, Ritmo, Tiempo, Fiesta, Tradición. \\ Sociability, Rhythm, Time, Festival, Tradition.
}

RESUMEN. Este artículo aborda la experiencia del tiempo de los participantes en la fiesta de las Fallas de Valencia. Asigna una importancia esencial al concepto de sociabilidad festiva, como forma fundamental de mediación entre la naturaleza, la comunidad y lo sagrado en la fiesta, constituyendo un eje central para los procesos (temporales) de transmisión de la tradición. Este artículo se propone analizar esta mediación temporal de la sociabilidad a través del análisis empírico de sus ritmos en la comunidad festiva. A lo largo del artículo se detallarán las transformaciones más significativas de la Semana Fallera, relacionadas con el cambio en el ritmo de la sociabilidad.

ABSTRACT. This paper is concerned with the experience of time in the Festival of the Fallas of Valencia. It attributes a central role to the concept of festive sociability. The first section summarises basic concepts. A second part describes the Festival. The third section deals with the community's collective memory and its cyclic sense of history. The fourth describes the annual cycle of the permanent festive sociability of the Falla. A fifth section is concerned with the intensification of the rhythm of festive sociability during the Festive Event; it produces a reorganisation of time and space which go along with other relevant changes at the personal and community levels. The participants have an opportunity to joyfully re-experience their time of childhood by means of play and humour; this helps them to search a deeper experience of the ephemeral in the context of a cyclic sense of time.

E-mail: llomadels@yahoo.es

${ }^{1}$ Una primera versión de este artículo fue presentada en el Congreso de la $F E S$, sección "Tiempo y sociedad", La Coruña, 24-26 de septiembre, 1998. Los datos de este artículo fueron recogidos en el contexto de un amplio estudio etnográfico sobre las Fallas (Costa, 1999).

Revista Internacional de Sociología (RIS)

Tercera Época, nº 31, Enero-Abril, 2002, pp. 113-136. 


\section{INTRODUCCIÓN}

El tiempo en las tradiciones festivas no puede comprenderse con independencia de sus formas y mecanismos de transmisión. En otro lugar (Costa 1999), y especialmente para el caso de las Fallas de Valencia, he mostrado la importancia de la sociabilidad festiva para dar cuenta de la transmisión de estas tradiciones. Entiendo, por tanto, que el análisis del ritmo de la sociabilidad puede decir mucho sobre el modo en que las tradiciones festivas presentan un sentido peculiar del tiempo que late en el fondo de sus procesos de transmisión.

El núcleo central de mi trabajo (Costa, 1998a y b; 1999; 2001a) sobre las tradiciones festivas está constituido por la teoría hermenéutica de la fiesta, particularmente en la versión presentada por Heidegger (1982) y Gadamer (1991), pero interpreto sus conceptos fundamentales a partir de la teoría de la sociabilidad de Simmel (1971). No obstante, la perspectiva utilizada en este trabajo incluye otros autores, en los que no puedo entrar aquí en aras de la brevedad, para caracterizar las cualidades y actividades específicas de la peculiar manifestación de la sociabilidad en la comunidad festiva, que conceptualizo como "sociabilidad festiva".

El evento festivo, que acontece durante los días de fiesta, se entiende en Heidegger (1995: 243; 1982: 71-77) como un "evento de apropiación" (Ereignis), que es, entre otras cosas, un ejercicio de intensificación de la memoria colectiva. Además, en la ontología de la hermenéutica, el evento reúne los vínculos que articulan los elementos que Heidegger denomina los "cuatro del mundo" (Das Geviert): el cielo y la tierra (la naturaleza), lo sagrado y la comunidad. El evento constituye un sentido peculiar de cercanía en relación con el mundo. Estos vínculos, que presiden las relaciones mundanas de los Cuatro, no son ni instrumentales ni objetivantes. El juego y el arte, la poética, la danza y la música, constituyen para la hermenéutica las formas paradigmáticas de expresión de tales vínculos en el contexto de la comunidad social. El evento festivo intensifica estas formas de expresión, generando además un acercamiento de la comunidad con el mundo (la comunidad se reconoce en su mundo) y una mayor aproximación e intensificación de vínculos entre los propios miembros de la comunidad celebrante.

Tanto Heidegger (1982: 61) como Gadamer (1991: 99 ss), cuando explican lo que consideran esencial en la fiesta, se refieren a un "acercamiento", un estrechamiento de los lazos entre las personas, una "re-unión" que se opone a cualquier forma de separación, segregación y aislamiento. Para Gadamer (1991) este proceso de reunión comunitaria que implica la fiesta representa una comunidad que supera las tensiones conducentes a la segregación y a la división interna. La fiesta es comunidad, quizá en su presentación más completa como tal comunidad, pues la fiesta es siempre fiesta para todo el mundo. Entonces, señala, "decimos que 'alguien se excluye' si no toma parte" (Gadamer, 1991: 99). 
Este poder de la fiesta para reunir a la gente no es coercitivo, sino que procede "de la intención que une a todos y les impide desintegrarse en diálogos sueltos o dispersarse en vivencias individuales" (Gadamer, 1991: 101).

Esta caracterización hermenéutica de los modos en que el evento festivo intensifica los vínculos mundanos y comunitarios puede hacerse operativa para la investigación empírica mediante el concepto de sociabilidad de Simmel (1971), que será preciso especificar para el caso particular de la "sociabilidad festiva".

Simmel (1971: 40 ss) encontró en la sociabilidad (una forma especial de la vida social) las mismas características del juego y del arte. La sociabilidad tiene una peculiar reflexividad, pues vuelve sobre sí misma: se tiene a sí misma como objeto de atención; y coloca los contenidos, objetivos y actividades instrumentales en un lugar secundario y dependiente. Esta característica de la sociabilidad lo es también del uso lúdico del lenguaje en un marco dominado por la sociabilidad. La "conversación sociable" se mantiene por el puro placer de hablar y sostener el vínculo interpersonal.

La sociabilidad es globalizante y su sentido del tacto (eje de su reflexividad) permite compatibilizar lo individual con lo grupal. Además, la sociabilidad tiene un peculiar democratismo basado en un principio de igualdad. Finalmente, la sociabilidad es terapéutica, constituyendo un buen pharmacos que es emancipador, y su reflexividad, expresada en una capacidad que comparte con el arte y el juego, permite crear una distancia (y una nueva aproximación) respecto a la vida y el mundo.

La idea principal que vincula la teoría hermenéutica de la fiesta y el concepto de sociabilidad de Simmel consiste en interpretar la forma lúdica y artística de la sociabilidad como parte de los vínculos no instrumentales (como el arte y el juego) que presiden las relaciones entre los miembros de la comunidad y median entre ésta y el mundo. Esta interpretación sirve para hacer más operacionales para la investigación empírica los densos conceptos de la hermenéutica, pues la sociabilidad tiene su fundamento en la interacción generada entre los actores sociales. De este modo, el evento festivo puede analizarse en términos de las formas de interacción características de la sociabilidad en la fiesta.

La sociabilidad festiva se refiere a la sociabilidad específica practicada por una comunidad que cuida de una tradición festiva. Puede comprenderse como un caso particular de la sociabilidad en los términos de Simmel, puesto que mantiene, e incluso radicaliza, sụ componente lúdico y artístico. No obstante, la sociabilidad festiva tiene una característica distintiva: su contenido y finalidad; las actividades de la celebración suponen una intensificación de la propia sociabilidad. Además, la sociabilidad festiva radicaliza las características centrales de la sociabilidad e incorpora nuevos agentes (una comunidad de familias, grupos de amigos y de vecinos, incluso participantes no registrados) y actividades específicas que interaccionan con las actividades generales descritas 
por Simmel en el marco de una comunidad (Costa, 1999: 46-55; 85-122). La sociabilidad festiva se manifiesta, y reproduce, mediante el ejercicio vital de formas de interacción situadas en actividades nucleares, como el juego (en la multiplicidad de sus formas), el humor, el comensalismo y el trabajo realizado para la fiesta. De este modo, la aproximación interpersonal que genera en la hermenéutica el evento festivo se traduce en términos sociológicos como una intensificación de la sociabilidad festiva. Además, el evento supone una mayor vinculación entre los Cuatro del Mundo: una más estrecha relación de mediación de la comunidad respecto a la naturaleza y lo sagrado. Los pasacalles y cabalgatas, los rituales y otras celebraciones, son parte central del evento festivo, constituyendo la manifestación de una intensificación de la sociabilidad e incluyendo una alta densidad de elementos del universo simbólico, así como un mayor acercamiento a los procesos y ritmos naturales. Sin embargo, vale la pena insistir en que estos aspectos del periodo festivo (a través de los cuales la comunidad se aproxima más a su mundo y se reconoce en éste) son posibles como resultado de unas prácticas y de un conocimiento que se encuentran en el ámbito de mediación de la sociabilidad; este conocimiento se desarrolla originariamente a partir de la sociabilidad permanente que existe en la comunidad.

El concepto de "cuidado reflexivo comunitario", que Heidegger (1995) usó especialmente para la obra de arte, se entiende a partir de la reflexividad y el tacto característicos de la sociabilidad de un grupo (Simmel, 1971); es un concepto útil para explicar las características de la sociabilidad permanente de la comunidad que cuida de la tradición festiva. La reflexividad de la sociabilidad festiva está caracterizada por la creación de una distancia (y proximidad al mismo tiempo), una "re-movida" en mi terminología (que es paralela a la que se produce en el arte y el juego) en relación con la vida y el mundo (Costa, 1999: 42 ss).

La idea de "ritmo de la sociabilidad" sitúa la concepción del ritmo social de Durkheim (1982) en la ontología y teoría hermenéutica de la fiesta anteriormente resumidas (e interpretadas a partir de Simmel). De este modo, el ritmo de sociabilidad tiene que ver con la globalidad de los Cuatro elementos, pues expresa el tiempo de sus vínculos en el mundo. Así, por ejemplo, como mostraré después, la pirotecnia (en articulación con los pasacalles musicales) es el reloj festivo: da el tiempo fundamental de la fiesta, constituyendo un ejercicio de aproximación a este "tiempo mundano". La pirotecnia, como fuego de la comunidad, en un proceso de intensificación, sigue los pasos del ritmo cada vez mayor de la sociabilidad, hasta que encuentra, en el momento del clímax durante la noche de la cremación de las fallas -el momento de máxima unión de la comunidad (y de ésta con la naturaleza y lo sagrado)—, al fuego mismo, al fuego del mundo.

En este contexto se aprecian dos tipos de ritmo en cada ciclo: uno para la sociabilidad permanente, $y$ otro para su intensificación durante el evento festivo. 
Además, el tiempo histórico de la comunidad supone un trabajo de memoria colectiva que permite la periódica puesta en marcha de cada ciclo rítmico de sociabilidad. Por otra parte, la sociabilidad, como ámbito de transmisión de la tradición, incorpora la experiencia presente (incluyendo su sentido del tiempo) en sus actividades centrales, como parte del conocimiento y de las prácticas que se elaboran de un modo sintético en los marcos dominados por la sociabilidad. Es decir, la tradición festiva establece una interacción constante con el presente a partir de su propio proceso de transmisión. Así, por ejemplo, durante el periodo festivo se produce una ruptura de los encajes temporales de las rutinas semanales, que da lugar a una reorganización del tiempo y del espacio, que incluye (aunque de modo subordinado) la moderna concepción del espacio/tiempo en el contexto de la tradición festiva. La familiaridad con esta experiencia de ritmo de la sociabilidad constituye un conocimiento para los actores sociales, que es parte de su identidad festiva, generando lo que denomino "tiempos fundamentales" de la fiesta: el "tiempo propio", efimero, pero lleno; el "tiempo cíclico", que articula la vida y la muerte con la renovación y la crítica; y el "tiempo biográfico", que supone un diálogo festivo con la experiencia de la infancia.

\section{LA FIESTA DE LAS FALLAS}

La Ciudad de València, situada en el área central de la costa Mediterránea de España, celebra anualmente una fiesta muy especial: La Festa de Les Falles. La gente utiliza igualmente las expresiones Las Fallas (en castellano), Les Falles o, también, Les Falles de Sant Josep para referirse a la Fiesta. Esta última expresión manifiesta el hecho de que el acontecimiento está asociado con la Festividad de San José, celebrada el 19 de marzo ${ }^{2}$. Durante la noche de San José se queman unas construcciones monumentales, satíricas y artísticas, realizadas con materiales efimeros, como la madera y el cartón, que son las Fallas como monumentos. Estas esculturas efimeras son el motivo y símbolo principal de la fiesta, que recibe así el mismo nombre (las Fallas). La medianoche de San José es el momento en que los participantes, visitantes y turistas, que han estado llenando las calles durante los días anteriores en masas de entre uno a dos millones de personas, toman completamente las calles y se reúnen en las plazas principales para asistir a la cremación de estas construcciones. Los fuegos concurrentes de esta noche mágica, extendidos por las calles y plazas de la ciudad, constituyen el acto central de un festival ígneo, acompañado de fuegos artificiales, que marca el clímax de la fiesta.

\footnotetext{
${ }^{2}$ Para la evolución socio-histórica de las Fallas durante la modernidad, ver Ariño (1992).
} 
RIS

REVISTA INTERNACIONAL DE SOCIOLOGIA

№ 31, Enero-Abril, 2002

La Falla es tanto el objeto como el sujeto de la celebración. La Falla, como un objeto, es la parte más visible de la fiesta en cada barriada de la ciudad. Consiste en una construcción, elaborada fundamentalmente a partir de madera, cartón y fibra de vidrio, que tiene (exceptuando las pequeñas fallas infantiles) una altura comprendida entre los cuatro y los treinta metros de altura. Son monumentos efimeros, que constan de complejas esculturas satíricas y que reúnen críticamente grupos de figuras de celebridades, gente de la vida corriente y caracteres míticos y de ficción, escenificando una gran variedad de situaciones imaginarias, fantásticas y propias de la vida cotidiana. Constituyen una especie de tableau vivant o teatro estático, representando temas populares y tópicos de la vida social.

La parte que está tras el escenario de cada Falla consta de una asociación de miembros activamente comprometidos que se llama Comissió Fallera, o también Falla. Este colectivo es el sujeto activo de la fiesta. El asociacionismo fallero es un fenómeno social importante en Valencia (una ciudad de aproximadamente 750.000 habitantes). Las Fallas son fiestas sostenidas por un movimiento que está geográficamente extendido. Constituye una red de asociaciones voluntarias que existe desde hace largo tiempo y que cuenta con cerca de 200.000 miembros en la Comunidad Valenciana. La unidad organizacional básica es la ya citada Comisión de Falla (Comissió Fallera), que normalmente comprende entre 200-300 miembros. Estas asociaciones voluntarias están altamente organizadas, siendo muy característica la manera en que combinan la racionalidad económica y administrativa con una intensa sociabilidad incardinada en una tradición profundamente enraizada. Además, existen vínculos organizacionales entre las Comisiones a nivel de localidades y de demarcaciones territoriales en la ciudad. Por otra parte, hay una asociación de los artistas que diseñan y construyen los monumentos $\mathrm{y}$, también, un organismo principal de coordinación de las actividades generales de la fiesta.

Cada asociación está implantada en un barrio de Valencia, aunque se asocia más claramente con un área de menor tamaño, normalmente un grupo de calles definido a partir de un cruce o plaza principal. Tiene su centro de actividad en un local comunitario conocido como el Casal, que puede ser llamado también Falla, dado que es el centro de la vida de su asociación. La totalidad del área urbana de la ciudad (y ahora de muchos otros pueblos y ciudades de la Comunidad Valenciana) está completamente dividida, desde el punto de vista de la fiesta, en secciones que atienden al emplazamiento de las Fallas y la red de sus Casales. El Casal es la base fisica para la variedad de actividades sociales que se encuentran en el corazón de la sociabilidad de la fiesta. Las actividades son muy variadas, incluyendo reuniones organizativas, juntas y asambleas, comidas, bailes, fiestas tipo discoteca para jóvenes, fiestas para niños, juegos sociales y de mesa, ver la TV, ensayar teatro, actividades para recoger dinero (con papeletas de lotería y realización de rifas), una variedad de prácticas musicales y muchos 
otros tipos de encuentros organizados por los falleros en el Casal o en las calles próximas.

La fiesta se extiende principalmente durante el mes de marzo, pero el clímax tiene lugar entre el 14 y el 19 de ese mes. Este periodo está organizado como un programa de acontecimientos y celebraciones, que presenta bandas musicales, eventos pirotécnicos, procesiones religiosas, como la Ofrenda de Flores a la Virgen ( $L^{\prime}$ Ofrena), cabalgatas satíricas y una gran variedad de acontecimientos lúdicos realizados al aire libre, que comienzan con la erección del monumento fallero (la Plantà) y finalizan con su destrucción por el fuego (la Cremà) durante la noche de San José. Esa noche acaba con un año de actividad cuyo objetivo principal es el diseño y la construcción (por parte de la Comisión o de un artista) de los monumentos satíricos esculturales que son las Fallas. El objetivo de ese enorme esfuerzo, que requiere una gran cantidad de energía y de dinero, es paradójicamente la destrucción de este mismo monumento. El trabajo y actividad de los falleros está destinado a la cremación del objeto que los representa, el monumento que han acabado de plantar unos días antes en algún lugar cercano a su Casal.

La fiesta también muestra que tradición y modernidad no están en irreconciliable oposición (Costa, 1999; 2001a). Las Fallas son tradicionales, pero ponen al día los viejos mitos y rituales del fuego. Son también sincréticas en la medida en que incorporan elementos de la experiencia contemporánea, produciendo un pastiche peculiar de lo viejo y lo nuevo. Al mismo tiempo, el festival es un acontecimiento moderno que da nuevo aliento para ejercitar cada año la memoria de la comunidad a través de la práctica de su particular y altamente organizado asociacionismo voluntario y sociabilidad festiva, incorporando el arte, el humor y la crítica satírica como medios para renovar la tradición. Desde esta perspectiva, las Fallas no son exactamente una creación moderna, sino que representan la persistencia del ritual y del mito en diálogo con la cultura de hoy. Consiguientemente, la tradición se enriquece y se hace más compleja; no solamente sobrevive a las fuerzas que la pueden erradicar o a los intentos de sustituirla, sino que también persiste en transformación como un ejercicio de la tradición misma para ponerse al día. Los viejos fuegos sacrificiales de los festivales ígnicos, tan típicos de la cultura carnavalesca europea (Frazer, 1963 y Bajtin, 1987), tienen una continuidad en el actual festival de las Fallas.

\section{EL TIEMPO DE LA FALLA COMO COMUNIDAD Y ASOCIACIÓN}

La historia de cada Falla es esencialmente oral: se hace presente fundamentalmente a través de la conversación cotidiana de los miembros, que actualiza de un modo activo la memoria colectiva del grupo. Pero esta práctica conversacional 
presupone, como mostraré después con el ejemplo de los pasacalles, un saber incardinado en hábitos corporales, que constantemente se reactiva en contextos dominados por la sociabilidad festiva, y siempre en el seno de los subgrupos que componen el colectivo. Esta memoria grupal constituye así un depósito común de experiencias, que el fallero utiliza constantemente para evaluar un aspecto $u$ otro de la experiencia presente, para tomar decisiones, para remitirse a puntos de referencia compartidos o para realizar un nuevo movimiento en un pasacalle. Otros medios complementan esta naturaleza conversacional-corporal de la transmisión de la historia del colectivo. Estos son el llibret y, especialmente, los objetos del Casal. Cada Falla dispone de un espacio en el Casal, destinado a su historia. Este lugar contiene las fotografias de las sucesivas falleras mayores, de los presidentes y de los monumentos. Los trofeos y las condecoraciones recibidas por la asociación, así como las fotografias conmemorativas, ocupan igualmente un gran espacio.

Los falleros cuentan el tiempo por "años falleros" o "ejercicios falleros", que finalizan, y comienzan, el 19 de marzo. En la vida cotidiana, sin embargo, más que citar un ejercicio u otro, es común recordar o referirse a un año aludiendo a una actividad concreta en relación con personas relevantes, tales como la chica que fue fallera mayor: "el año de Loli, ¿te acuerdas de los disfraces?". Otros acontecimientos importantes para el colectivo, como por ejemplo un traslado o ampliación del Casal o la consecución de un determinado premio para el monumento, organizan las referencias de los participantes. Igualmente, los actores festivos distinguen amplios periodos dentro de la historia de la Falla, caracterizados por la activa presencia de una determinada generación. El momento de la fundación de la Falla, incluso si se trata de una Falla de creación reciente, es explicado en términos de la continuidad entre generaciones. Uno de los fundadores de una Falla de 25 años dijo:

"Yo creo que es una herencia porque un día vinieron los padres, esos padres tuvieron hijos, que se casaron /.../ Estos han tenido hijos y son falleros. Yo creo que eso es herencia de los primeros que se apuntaron: padres, hijos y luego nietos. Ahora todos se encuentran en la fiesta, pero claro porque los padres están en la fiesta, porque si no, no puede ser".

Para los participantes, cada Falla es diferente a otra y, como dicen frecuentemente, "tiene su propia personalidad", asociada a las particularidades de su historia en el contexto de una barriada. Esta personalidad depende también de los tipos concretos de actividades que se realizan, de las personas que las han promovido, de las nuevas ideas que se han desarrollado con éxito e incluso de los fracasos que han caracterizado la implementación de otras propuestas. En este sentido, los participantes señalan que las Fallas oscilan en el tiempo - "cada falla tiene subidas y bajadas", dijo un fallero experimentado- en función 
del nivel de actividad existente en su vida social y de la consolidación de las actividades que se proponen. Esta personalidad de cada Falla ejerce, por otra parte, una fuerte presencia en la biografia de los miembros. Una buena parte de las relaciones sociales de cada participante está entretejida con la historia peculiar de la Falla. En este sentido no es frecuente cambiarse de una Falla a otra. Muchos participantes incluso siguen en la misma Falla a pesar de un cambio de residencia. Las Fallas del casco viejo de Valencia están formadas básicamente por familias que, habiendo cambiado de barrio, mantienen todavía su vinculación con éste a través de su Falla.

En las Fallas investigadas en este trabajo, todas ellas de origen reciente y situadas en barrios obreros de nueva creación, es posible establecer dos periodos esenciales para su evolución: un momento de fundación y otro de consolidación. La sociabilidad es esencial en ambos periodos. La fundación es realizada por un pequeño grupo de familias y de amigos del barrio que deciden constituir una Comisión. Entre las razones, explicitadas por los participantes, se incluye un énfasis en la creciente ausencia de relaciones sociales en los barrios de nueva creación, donde muchos vecinos no se conocen. Algunos de los fundadores proceden de zonas cercanas, y cuentan con una experiencia previa en otras fiestas locales. Una gran cantidad de miembros fundadores, con frecuencia más de la mitad, son inmigrantes.

El periodo de consolidación está relacionado con una mejora en la contabilidad y en la organización de la Comisión, así como con el desarrollo de modos particulares de canalización de la sociabilidad festiva, que estabilizan una variedad de actividades, tales como teatro, karaoke, baile, música, etc. Normalmente, en las Fallas estudiadas, este periodo de consolidación sobreviene si el grupo inicial consigue sortear algunas situaciones de crisis económica o, también, de crisis de sociabilidad. Entre las últimas cabe señalar la importancia de las disputas sobre la identidad valenciana, que repercutieron notablemente en la fiesta a finales de la transición democrática. Tanto en el caso de la crisis económica como en el de la sociabilidad, la Falla se sostiene y recupera el proyecto festivo compartido, sólo si un grupo de familias y de amigos consigue devolver la confianza con una clara gestión e impone los valores básicos asociados con la sociabilidad. Una parte importante de estos valores tiene que ver con las "viejas amistades", que, como señaló un veterano fallero, están originadas en el barrio y se encuentran por encima de cualquier perspectiva ideológica concreta. En cualquier caso, la Falla subsiste si un grupo directivo es suficientemente poderoso para relanzar la sociabilidad festiva.

Así pues, la memoria colectiva de la Falla es condición necesaria para la sociabilidad festiva, pero al tiempo depende de ésta para el propio ejercicio concreto de las actividades sociales. Las referencias al tiempo y a la personalidad de la Falla, así como las situaciones de crisis, tienen también como referente a esta rica sociabilidad comunitaria. A continuación veremos cómo esta sociabilidad, y su ritmo, estructuran un ciclo festivo. 
RIS

REVISTA INTERNACIONAL DE SOCIOLOGÍA

№ 31, Enero-Abril, 2002

XAVIER COSTA GRANELL

\section{EL CICLO ANUAL: EL EJERCICIO FALLERO}

Las Fallas tienen un calendario particular que gira alrededor del 19 de Marzo, fecha que marca el final y el comienzo del Año Fallero. Los participantes que viven la fiesta con intensidad rigen una buena parte de su existencia en función de este calendario. El Año está claramente dividido para el participante en dos partes: el largo tiempo de preparación de la fiesta, y el tiempo festivo. Los participantes se refieren habitualmente a estos dos periodos con expresiones tales como "durante el Año" y "los días de Fallas". Este último periodo incluye una transición, cuyo eje es la fecha de la Presentación de la Fallera Mayor. Este ritual de presentación pública de la asociación, realizado normalmente durante el mes de Febrero, marca el inicio de la transición hacia el tiempo festivo, que adquiere su máxima expresión durante la Semana Fallera.

\section{Tiempo de preparación y tiempo de fiesta}

Esta clara oposición entre "tiempo de preparación" y "tiempo de fiesta" podría hacer pensar que durante todo el año no se vive la fiesta o que en los días de fiesta no se prepara nada. Sin embargo, el calendario fallero incluye actos festivos y celebraciones durante todo el año y exige también una disposición para el trabajo colectivo durante los días de fiesta. De ahí que la percepción de la articulación entre "tiempo festivo" y "tiempo profano" dependa del modo de participar en las estructuras de la sociabilidad permanente de la fiesta. En el interior de las comisiones falleras hay un claro contraste, constantemente explicitado por los actores festivos, entre dos tipos de falleros, que configuran dos grandes grupos, manifestando dos maneras de entender la fiesta. Por un lado, están los "falleros-falleros", que viven la fiesta todo el año, adquiriendo un claro compromiso con la asociación. Por otro lado, se encuentran aquéllos que el fallero comprometido denomina "falleros de cuatro días", que sólo acuden durante los días de fiesta y frecuentemente retrasan sus aportaciones económicas. La sustentación de la sociabilidad permanente de la fiesta depende así de una parte del colectivo, que realiza además el trabajo de preparación y obtención de recursos.

Sociabilidad y recursos constituyen las dos precondiciones para el desarrollo de la fiesta. Las diversas Fallas varían en el modo de resolver ambas cuestiones, y presentan diferentes oscilaciones en sus ritmos de acercamiento al tiempo festivo en función de la articulación entre sociabilidad y recursos económicos. En general, cuando una Falla tiene una sociabilidad intensa resulta más fácil resolver cualquier asunto económico o administrativo. Por otra parte, el disponer de mayor cantidad de recursos permite realizar un mayor número de actividades durante el año. En el proceso de construcción de la Fiesta la sociabilidad festiva aparece como condición necesaria para la generación de recursos. En este 
sentido, la capacidad de la Junta Directiva, y especialmente el carisma del Presidente y de la Fallera Mayor, es fundamental para sostener la conexión entre los subgrupos de participantes e impregnar al colectivo con su entusiasmo para resolver cualquier problema, incluyendo la obtención de recursos.

Esta sociabilidad festiva permanente se basa también en el disfrute cotidiano de otro tiempo festivo: la cena semanal de los viernes, la paella de los domingos, el trabajo o la estancia diaria en el Casal tras la jornada laboral constituyen modos de vivir la fiesta durante el tiempo de su preparación. El "fallero-fallero" tiene, pues, más "tiempo festivo" que la persona que no se implica tanto en la fiesta.

El contraste entre tiempo sagrado (festivo) y tiempo profano se produce en las Fallas. Pero no existe una oposición tan tajante y generalizada como a veces se supone. El fallero que vive la sociabilidad permanente de la fiesta no separa ambos tiempos tanto como el mencionado "fallero de cuatro días", que acude al final, o como el que vive la fiesta desde fuera del Casal. Según el grado de participación, el tiempo festivo tiende a expandirse e inunda con "partes festivas" la existencia cotidiana de los participantes. De cualquier modo, el contraste que los participantes viven en la fiesta es el que se produce entre el tiempo festivo y el tiempo de la jornada laboral. La separación se produce entre la fiesta y la necesidad de trabajar para obtener recursos para vivir. Otras formas de trabajo, no obstante, existen dentro del tiempo festivo. En otro lugar (Costa, 2000) he conceptualizado este tipo de "trabajo sociable festivo". Este trabajo festivo está profundamente vinculado con las formas concretas de la sociabilidad permanente de la fiesta, y adquiere frecuentemente una vivencia de tiempo de fiesta, incluso de lo que denominaré después "tiempo propio". Esta forma de trabajar para la fiesta, en el marco de su sociabilidad, es entendida por el "fallero-fallero" como un compromiso, que frecuentemente formula mediante la expresión "estar ahi'"3. Este tiempo dedicado al trabajo festivo es, por tanto, un importante signo de identidad en la Falla ${ }^{4}$.

\section{El largo periodo de preparación de la Fiesta}

La sociabilidad permanente de la fiesta no tiene el mismo ritmo durante todo el año. Éste se acrecienta en la medida en que se avanza hacia la primavera, adquiriendo una progresión extraordinaria desde que se comienza a preparar la

\footnotetext{
${ }^{3}$ En esta ocasión, no obstante, voy a referirme especialmente al tiempo festivo tal y como se vive desde la perspectiva del participante en la activa vida social de las Comisiones de Falla.

${ }^{4}$ Sobre la importancia del tiempo dedicado al trabajo para la Falla como expresión de la identidad festiva, ver Costa (2001b).
} 
RIS

REVISTA INTERNACIONAL DE SOCIOLOGÍA

№ 31, Enero-Abril, 2002

XAVIER COSTA GRANELL

ceremonia de la Presentación. Finalmente, la Semana de Fallas rompe con el encaje temporal propio de las rutinas semanales del resto de los días del año, que es sustituido por el complejo entramado de reuniones y encuentros informales y por las celebraciones contempladas en el programa festivo. Durante esa semana se produce un cambio en la percepción del tiempo, que está asociado a otras transformaciones personales y colectivas.

La fiesta tiene un primer periodo de recomposición después de la Cremà. Hay una nueva Junta Directiva y se establecen los nuevos planes, se analizan los errores, etc. El día festivo de la Apuntà (registro oficioso de nuevos falleros), realizado una semana después de la Cremà, contribuye a mantener la atmósfera festiva en el Casal. Constituye una primera celebración del "nuevo año", pero al mismo tiempo actúa como facilitador para la transición de salida del ritual, un proceso que finaliza definitivamente en Pascua.

Un segundo periodo, habitualmente difícil, se sitúa entre mayo y septiembre. Es un periodo de relativa disolución de vínculos. Algunos miembros retrasan sus pagos, o no colaboran especialmente en los trabajos destinados a recoger dinero. Esto puede generar, si no ha finalizado el ejercicio con un amplio superávit, serios problemas para mantener el pago regular al artista o hacer frente a los gastos del Casal. Durante los meses del verano la asistencia al Casal disminuye considerablemente, así como las cenas o reuniones organizativas. No obstante, en algunas Fallas cabe una excepción, tal como ocurre en algunas de los barrios de los poblados marítimos, donde la Falla puede convertirse en punto de referencia para pasar unas vacaciones baratas "sin salir de casa". Afortunadamente, la Falla no necesita realizar ningún gasto importante durante este periodo de carencia económica y de baja intensidad de vida social.

Un tercer periodo comienza en octubre y finaliza con la llegada de la paga extraordinaria de Navidad. Se caracteriza por la incertidumbre en las cuestiones económicas. La venta de la lotería de Navidad produce en ocasiones retrasos en los cobros. Afortunadamente, el ritmo de la sociabilidad aumenta, los falleros acuden al Casal y van poniéndose al corriente en el pago de las cuotas fijas mensuales. No obstante, es común realizar rifas por estas fechas con la intención de obtener dinero fresco para poder cumplir con los pagos mensuales al artista, alquiler del Casal, etc.

Un cuarto periodo comienza en Navidad y Año Nuevo y alcanza hasta la Presentación y la Semana Fallera. Es un periodo de estabilización de la vida económica, de intensificación de la vida social y de abundante trabajo para organizar una variedad de aspectos de la fiesta, principalmente el Llibret (revista anual) y la ceremonia de la Presentación, un acto que requiere de un gran esfuerzo por parte del colectivo, constituyendo el primer gran acto público de la Falla y el que quizá requiere más trabajo por parte de todos. Como un participante señaló: "cuatro horas de Presentación requieren varios meses de trabajo". Esto supone un gran número y variedad de reuniones para preparar 
el acto, que movilizan a la totalidad del colectivo. El desafio que supone la Presentación constituye el gran acelerador del ritmo de la sociabilidad festiva, que conduce finalmente, con una intensidad aún mayor, hasta la Semana Fallera. La Presentación supone un test inicial respecto a la capacidad de trabajo y de movilización de la Falla para realizar los actos y celebraciones de los días de fiesta. Si la Presentación tiene éxito, la Comisión adquiere nueva energía y confianza para llevar a buen término el tramo festivo final.

El colectivo cuenta, tras la Presentación, con la incorporación de una buena parte de los falleros que acuden al final del ejercicio para desarrollar el programa de fiestas. El periodo que va de la Presentación a la Semana de Fallas tiene así una mayor densidad de reuniones, que inciden notablemente en el solapamiento de los distintos grupos de falleros, contribuyendo a crear un mayor sentido de colaboración y de unión en el proyecto festivo. Los participantes sitúan en este periodo el surgimiento de lo que denominan "una fuerza misteriosa que une", generando una mayor "armonía", "unión" y "ambiente", y que a veces explican también mediante el uso de metáforas tales como un sueño, una fantasía, una nube misteriosa, una piña, un árbol al que le brotan nuevas hojas, etc.

\section{EL RITMO DE LA SEMANA FALLERA: TRANSFORMACIONES PERSONALES Y COLECTIVAS}

El ritmo de la sociabilidad festiva se intensifica durante la Semana Fallera al mismo tiempo que se produce una variedad de transformaciones personales y grupales. Señalo a continuación cuatro aspectos que caracterizan, aunque no agotan, estas transformaciones. El tiempo constituye así el eje a través del cual la tradición festiva sigue apropiándose de la memoria colectiva de una comunidad y continúa su transmisión en relación con la experiencia presente.

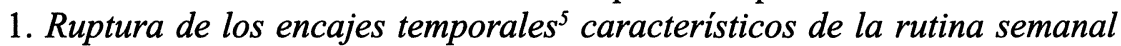
y su sustitución por la actividad en la comunidad festiva. El ejemplo más claro tiene que ver con la vida familiar, cuyas rutinas semanales desaparecen o se alteran considerablemente para ajustarse a la dinámica más amplia de generación de la "gran familia" de la propia comunidad festiva. El tiempo de sueño se reduce y/o cambia, coexistiendo con una sensación de caos, al tiempo que se atienden numerosas y variadas actividades en la fiesta. Los actores festivos

\footnotetext{
${ }^{5}$ Utilizo aquí el concepto de "encaje de tiempo" de J. David Lewis y Andrew J. Weigert (1992: 100, 116, 121). Estos autores, sin embargo, no prestan atención al tiempo festivo en el contexto de una sociedad moderna. De este modo, no observan que las tradiciones festivas utilizan elementos de la modernidad como parte de su diálogo con el pasado, mediante el
} 
son totalmente conscientes de esta transformación, e incluso bromean en las entrevistas: "En Fallas no sabes por donde vas: cuando yo subo al piso a por un bocadillo, entonces mi mujer baja por las escaleras", "los niños se olvidan de que tienen padres", "yo lleno la nevera y el congelador y que se las apañen", "las mujeres tienen bula para todo". Esta ruptura de rutinas en la familia nuclear moderna comporta un primer estadio de individualización, con una independencia relativa de los miembros que, en un segundo estadio, se reagrupan en el más amplio contexto de la comunidad festiva. Así, por ejemplo, las funciones de control de los niños usualmente realizadas por el padre y la madre son asumidas por colectivos (hombres y mujeres adultas) en las actividades festivas concretas. Por otra parte, a esto se añade la delegación de una parte de la autoridad en el Presidente y en la Fallera Mayor, otro aspecto que permite a los adultos cierta relajación para, como explicaré después, explorar sư tiempo de la infancia mediante el juego y el humor.

2. Alto ritmo y expansión de la sociabilidad festiva. Los participantes son conscientes de la extraordinaria progresión del ritmo festivo de actividades, así como de su gran número e intensidad emocional. Tanto los adultos como los niños indican que hay una alta frecuencia de reuniones informales y encuentros, que discurren paralelamente a otras actividades formales, rituales y celebraciones del programa festivo. Una ex-fallera mayor infantil señalaba: "En Fallas siempre estás reunida con tus amigos". Por otra parte, la sociabilidad festiva "sale a la calle", ensanchando su espacio de juego. El comensalismo en la calle y los pasacalles y celebraciones en el exterior constituyen las actividades colectivas más frecuentes. Esta intensificación del ritmo e intensidad de la sociabilidad tiene una variedad de consecuencias, que se explicitan en el discurso de los participantes, tales como la intensificación de las emociones, el incremento del sentido de proximidad entre los miembros y la generación de una mayor unión en el colectivo.

3. Estas características de la sociabilidad están asociadas con una transformación en el espacio y el tiempo. La comunidad festiva realiza una

\footnotetext{
ejercicio activo de memoria colectiva. Además, la concentración de estos autores en las condiciones temporales de las organizaciones de la modernidad y en lo que denominan "tiempo físico" les conduce a una comprensión unilateral del sentido de la "escasez" del tiempo. Este aparece relacionado con la multiplicación de actividades entre dos puntos del "tiempo físico", con la competitividad en las organizaciones y con patologías. En la fiesta, no obstante, existe una percepción del tiempo "escaso" como tiempo efimero, que (como mostraré más tarde) tiene otra naturaleza. En la fiesta, el tiempo puede también percibirse como escaso, siendo también un tiempo lleno, cuando realizamos actividades que nos gustan, aunque éstas se multipliquen en un intervalo o marco temporal. El tiempo festivo, por otra parte, como hacen explícito los actores festivos, es un buen phármakon.
} 
apropiación y reorganización del tiempo y del territorio festivo. En esta expansión, marcaje y apropiación del espacio en relación con el tiempo, ejercen un papel fundamental actividades como el comensalismo, la pirotecnia, la música y la movilización general de la Comisión mediante los numerosos pasacalles y actividades desarrolladas en el barrio. El complejo entramado de actividades se vale de otras formas, distintas a las del tiempo del reloj moderno, para marcar su tiempo y espacio. En este sentido, la comunidad festiva establece un diálogo con formas tradicionales de marcaje espacio-temporal de la actividad o celebración. Este diálogo incorpora la presencia de elementos de la experiencia contemporánea del espacio y del tiempo y el consentimiento de las instituciones modernas, tales como el Ayuntamiento. Los límites territoriales de la fiesta se expanden hacia las calles adyacentes, el Casal se amplía con el uso de un amplio toldo que cubre la calle. Todo el área queda cortada para el tráfico con el permiso del Ayuntamiento, que proporciona la correspondiente señalización y la vigilancia policial. Es importante señalar que los participantes afirman de modo general que consideran ese nuevo espacio como propio.

Otro tanto ocurre con el tiempo, cuyo marcaje, siempre en relación con una actividad festiva, corre a cargo de la pirotecnia. El pasacalle pirotécnico denominado Despertà da comienzo al día festivo. Las celebraciones son precedidas de tres avisos de carcasa. El corazón del día y de la noche se anima con el estruendo de la mascletà y el castell de fuegos artificiales. Además, la intensificación del ritmo de actividades que se produce en el último tramo festivo, que sucede a la Presentación, se corresponde con series crecientes de explosiones de petardos realizadas por los niños en las calles del barrio. En muchos de estos casos, la pirotecnia contribuye también a marcar también el espacio de las actividades festivas. Esta transformación del tiempo y del espacio, vale la pena insistir, requiere la presencia constante de los participantes en las calles, que manifiesta el predominio de las nuevas reglas festivas mediante los pasacalles y las celebraciones al aire libre. En este sentido, no solamente la pirotecnia, sino la música, las flores, el monumento efimero, el cuerpo en movimiento en los pasacalles y los vestidos, contribuyen a señalar el tiempo y el espacio de fiesta. Por otra parte, todos estos elementos tienen un denominador común: su naturaleza transitoria, efimera, que corresponde con la naturaleza del tiempo de marzo ${ }^{6}$.

4. El re-encaje temporal de la Fiesta. Tras la ruptura del encaje temporal de la rutina semanal, el tiempo del reloj constituye en la fiesta únicamente una

\footnotetext{
${ }^{6}$ Heidegger (1985) se refiere al tiempo de marzo al hilo de su discusión de la Fiesta en relación con Hölderlin. Märzenzeit es el tiempo de lo efimero, transitorio y perecedero. Más detalles sobre el sentido de lo efimero en la sociabilidad y los símbolos fundamentales de las Fallas, pueden verse en Costa (1996; 1999: capítulos 7 y 8; 2001b).
} 
RIS

REVISTA INTERNACIONAL DE SOCIOLOGIA

№ 31, Enero-Abril, 2002

XAVIER COSTA GRANELL

ayuda para negociar con la autoridades el marco festivo o para hacer público un programa de fiestas para el público en general. Otra temporalización preside el ritmo festivo. Se desenvuelve a través de las actividades y celebraciones concretas, que se suceden y solapan entre sí. Este saber activo, que pasa por el cuerpo, es parte de la memoria colectiva. Los participantes las han realizado en otras ocasiones, y comparten un conocimiento sobre sus características y sentido, un saber que es fundamentalmente tácito y que sólo se aprende mediante la participación en la fiesta. Este re-encaje temporal de la fiesta, que ha supuesto un aumento vertiginoso del ritmo de la sociabilidad festiva, finaliza, no obstante, de modo abrupto, en la Cremà, el momento en que el corazón del tiempo del grupo, marcado por la pirotecnia, entrega su ritmo al fuego. Este hecho tiene implicaciones considerables, como explicaré en la sección siguiente, en la percepción del tiempo festivo que tienen los participantes.

Estas características del tiempo festivo, asociadas con las trasformaciones anteriores, presentan un denominador común. Constituyen un ejercicio de diálogo y transmisión de una tradición festiva. La vuelta a una imagen anterior de la familia en el seno de la comunidad festiva, la intensificación de la sociabilidad callejera tradicional valenciana y la vuelta a un sentido anterior del espacio y del tiempo, se producen incorporando instrumentos e instituciones de la experiencia contemporánea. $\mathrm{La}$ familia nuclear, el asociacionismo voluntario y el marco del espacio y tiempo modernos, que sancionan las instituciones, han configurado una experiencia que utiliza la tradición festiva para "ponerse al día", para seguir siendo transmisión de las cosas. Como ha señalado Gadamer (1991: 112,117), en la tradición se aproximan también los tiempos. En este sentido, como hemos visto, la tradición festiva produce una interacción entre su propio tiempo y el tiempo moderno del reloj.

El olvido de este sentido de la tradición, como puesta en relación de los tiempos, que aproxima la memoria y produce una renovación efectiva, una "transmisión de las cosas", podría hacer pensar que las Fallas son una fiesta exclusivamente moderna. De hecho, la fiesta incorpora gran cantidad de nuevos elementos, que integra el viejo ritual ígneo desde el siglo XVIII hasta el momento actual. Algunos de éstos son el asociacionismo voluntario, ciertos aspectos de la racionalidad económica, los nuevos materiales de construcción del monumento, las escenas de la política actual, etc. Sin embargo, el abigarrado pastiche de la fiesta, cuya capacidad para el sincretismo sorprende, obliga a leer de otro modo la traducción que elabora la tradición de las Fallas. Las formas básicas de la sociabilidad festiva, los mitos o los viejos símbolos del monumento, la sátira, la dinámica del ritual, etc., aparecen siempre de nuevo, como la semilla ${ }^{7}$ reproductora que salta hacia el presente. Heidegger y Gadamer gustan de poner

\footnotetext{
${ }^{7}$ Ricardo Sanmartín (1996: 128) se refiere a la tradición como "semilla del presente".
} 
el ejemplo del monumento, tan pertinente en el caso de las Fallas, para explicar esa interacción en el tiempo que es la tradición. Señala Gadamer (1991: 117): "la tarea de poner juntos el hoy y aquellas piedras del pasado que han perdurado es una buena muestra de lo que es siempre la tradición. No se trata de cuidar los monumentos en el sentido de conservarlos; se trata de una interacción constante entre nuestro presente, con sus metas, y el pasado que también somos". Pero esta interacción entre pasado y presente se realiza en la tradición a partir de sus tiempos fundamentales.

\section{LOS TIEMPOS FUNDAMENTALES DE LAS FALLAS}

Me refiero aquí solamente a tres tiempos de la fiesta: el tiempo propio, el tiempo cíclico y el tiempo de la biografía. No puedo ocuparme en este artículo de otros aspectos del tiempo de fiesta, así como de su vinculación con el tiempo moderno del reloj y con la dinámica de las instituciones y organizaciones de la sociedad valenciana.

\section{El tiempo propio: un tiempo efímero y lleno}

Los actores festivos coinciden en las características del tiempo festivo, aunque para cada grupo esto adquiere matices ligeramente diferentes. La primera es una especie de desengaño que se experimenta a posteriori: el tiempo festivo es demasiado breve, corto, en relación con las expectativas que despierta como tiempo absoluto, potencialmente lleno de cosas que se desean hacer. El participante se acerca presuponiéndolo amplio, y lo vive muy intensamente, como tiempo lleno, y, sin embargo, tras la fiesta es sentido como demasiado breve, escaso y efímero. Los que más cosas esperan hacer durante este tiempo de Fallas son los niños. Igualmente son los que aparentemente más disfrutan (al menos afirman "pasárselo muy bien") y consiguientemente son también los que experimentan una desilusión mayor por la brevedad de este tiempo de fiesta: "Estos días son muy cortos, todos juntos parecen un solo día. Pasan muy rápido, como si fueran sábado y domingo". Los adultos señalan también que el tiempo festivo pasa muy pronto, y que les gustaría que fuese más largo. Una experimentada fallera dijo: "La semana de Fallas pasa enseguida, desearías que fuera más larga". Normalmente señalan dos razones para explicar esta sensación de brevedad: el realizar muchas cosas y el estar haciendo algo que les gusta ("La Semana de Fallas pasa volando, tienes tantas cosas que hacer. Se va con un plis, vista y no vista").

La Semana de Fallas también es entendida como breve en relación con el resto del año, particularmente cuando se contempla la cantidad de trabajo que ha sido necesario para hacer la fiesta. En este sentido, el tiempo festivo constituye 
RIS

REVISTA INTERNACIONAL DE SOCIOLOGIA

№ 31, Enero-Abril, 2002

XAVIER COSTA GRANELL

el fruto de un largo esfuerzo, "la culminación de un año de trabajo", que en ocasiones es entendido como un sacrificio. En otras ocasiones, sin embargo, el tiempo festivo es comparado con un sueño o fantasía, especialmente en el caso de la Fallera Mayor.

Pero la sociabilidad festiva permanente atiende también a un sentido del tiempo que, según Gadamer, acerca a la fiesta y al arte. Este "tiempo propio" es un tiempo lleno, que invita a demorarse para retener lo efimero, lo fugitivo, el sentido de la finitud ${ }^{8}$. Una fiesta tan artística como las Fallas sabe doblemente de este tiempo. Algunos de sus símbolos fundamentales pueden evidenciarlo para un observador no participante: las flores, la música, el estallido de colores de la carcasa, el arte del monumento efimero. Al ser preguntado por la presencia de las flores en la fiesta, un experimentado fallero señaló: "Están unidas a la fiesta. Hay tres o cuatro cosas que, si no estuvieran, no sería posible comprender la fiesta: traca, música, flores ... Si a esto le añades que las flores son algo efimero, que su vida es corta y que pueden romperse fácilmente, como las otras cosas de la fiesta, pues ya lo tienes". Pero este sentido de lo efimero corresponde con un momento de eternidad. Supone la sensación de tener, como dijo un veterano fallero, "todo el tiempo del mundo" en un instante lleno que pasa fugitivamente. Por otra parte, es un tiempo de creación, similar al tiempo de producción de una composición artística o musical, que pasa intensamente sin que nos demos cuenta mientras estamos sumergidos en una actividad que nos gusta, que no nos cansa porque conecta y saca a la luz aspectos de nuestro ser propio.

Esta sensación del tiempo se tiene incluso en las circunstancias en que hay que trabajar para la fiesta. Una vez participé en la reparación de un armario del Casal con otros dos falleros, uno de los cuales era oficial de carpintería y gran fallero. Lejos de atender la faena desde la perspectiva profesional, Amado nos invitó a enroscar los tornillos poco a poco, disfrutando de cada instante. Fue una fiesta: hicimos turnos espontáneamente para sujetar la puerta, manejar el destornillador y contar anécdotas chistosas. ¡Nadie sabe el tiempo que pasó! Amado dijo: "Aquí tenemos todo el tiempo del mundo". El tiempo festivo daba cabida a su tiempo propio. Su corazón, ya enfermo, lo buscaba allí, en la fiesta, fuera del taller. Amado murió unos meses después. Le estalló el corazón mientras hacía su jornada regular de trabajo en la carpintería.

El tiempo festivo se presenta como completo, se vive como lleno y, cuando pasa, es sentido como escaso, corto, efimero, en relación con lo lleno que es mientras se vive. Sin embargo, como en el caso del tiempo de una pieza musical, las Fallas tienen su propio tiempo, que interpretan los participantes. Se trata, además, del mismo tiempo tanto para la fiesta como para el monumento. La

${ }^{8}$ Gadamer (1991:103 ss). También las notas anteriores 6 y 7 . 
fiesta dura mientras el monumento artístico está en pie, y en ambos casos la preparación, o construcción, es anual. Además, los actores festivos señalan siempre que no sería posible disponer de un día más de fiesta, que su duración es la justa: "es exactamente el tiempo que aguanta el cuerpo", dijo una fallera. El tiempo propio de la comunidad festiva es pues también el tiempo del arte en la Falla'.

\section{Tiempo cíclico: muerte, renovación y crítica}

La naturaleza efímera del tiempo festivo está articulada con su carácter cíclico. Algunos actores apuntan incluso al dolor que produce esta sensación de brevedad, cuando sobreviene el final de la fiesta. Al ser preguntada sobre lo que sentía después de la Cremá, una ex-Fallera Mayor señaló: "Cansancio y pena a la vez porque se termina lo que has estado preparando durante un año y duele que pase tan rápido. Los últimos días se pasan sin darte cuenta, y todo lo que has preparado durante un montón de tiempo hace ¡pam! y nada”. Pero igualmente los actores festivos siempre señalan la llegada del impulso de esperanza que apunta hacia un nuevo comienzo, y dicen esforzarse "por mejorar las cosas el año próximo". El tiempo cíclico implica muerte y renovación. En este sentido, la imagen del Fénix es predominante en el discurso fallero. A diferencia de otras maneras de entender la crítica, la crítica satírica de la Falla exige un cambio efectivo y no está separada de la belleza, de la fantasía y de la ensoñación. Un artista fallero señaló:

La Falla comienza con un sentido crítico del humor. El contenido de esta crítica es social, económico, político. El sentido de esto es que la Falla se planta, se expone al público y se quema, para nacer inmediatamente de nuevo. Aquí hay una cosa fantástica que algunas personas no comprenden. Es necesario quemar las cosas. Esto no es como la actividad de los bancos, que acumulan las cosas, no, no. Aquí quemamos las cosas para que vuelvan a resurgir de las cenizas. Este es el sentido, interesante de las Fallas, y yo lo encuentro bello.

En este sentido las Fallas están cerca del arte y más allá de lo que Heidegger (1994: 21) ha llamado "estructura de emplazamiento" (Ge-stell), que es para él la esencia de la técnica moderna. Esta estructura que emplaza es acumulativa, aseguradora y provocadora respecto a la naturaleza; además, se corresponde con la expresión violenta del pensamiento metafísico. En este sentido, las Fallas son no-metafísicas. Algo similar ocurre con respecto al tiempo. La actitud

\footnotetext{
${ }^{9}$ Para la conexión entre la fiesta y el arte en las Fallas, ver Costa (1998).
} 
RIS

REVISTA INTERNACIONAL DE SOCIOLOGÍA

№ 31, Enero-Abril, 2002

XAVIER COSTA GRANELL

acumulativa y aseguradora ("el tiempo es oro"), que subyace a la comprensión del tiempo como útil o instrumento manejable a voluntad, no encaja en la perspectiva de la fiesta. Además, la catarsis de fuego de la Cremà constituye una purificación no ascética, que comporta una destrucción y una renovación. Este carácter cíclico está presente también en la misma organización de la comunidad. Como señalaron dos experimentados falleros en una entrevista de grupo:

Nosotros hemos tenido monumentos grandes, pequeños y medianos. Pero sería lo mismo si plantáramos un pino y lo quemáramos /.../ Es una renovación, una renovación total /.../ Esa noche todos hemos muerto [iExactamente!, ¡exactamente!]. No existimos como Comisión, hemos desaparecido totalmente. El Presidente dimite. [Toda la Junta Directiva dimite]. Solamente hay una persona, el primer vocal, que continua. [Es lo que él ha dicho antes, una palabra que me gusta mucho: renovación] /.../ Hay una renovación de todo, es general. [Sí, es una continua renovación.]

\section{El tiempo biográfico: exploración de la infancia con el juego y el humor}

Las formas de juego y el humor que caracterizan la sociabilidad festiva permanente se intensifican durante los días de la fiesta, la cual tiene también un lugar para otros juegos típicos del periodo festivo. El más característico es el de jugar con petardos, una actividad básicamente realizada por niños, pero que encuentra también interés entre los adultos. Estos recuperan durante estos días una buena parte de las habilidades e inventiva de su infancia, mientras acompañan o enseñan a sus propios hijos. Los adultos también practican otros juegos e incluso desarrollan lo que algunos denominan "aventuras", tanto en el Casal como en la calle. El humor igualmente ayuda a los falleros a romper con la seriedad y formalidad requerida para las rutinas de la vida. Los actores festivos caracterizan frecuentemente este proceso generado por el ambiente de fiesta con frases que incluyen la expresión "desmadrarse". Una fallera señaló: "perdemos la seriedad y nos desmadramos".

Esta evitación periódica de los aspectos más serios y condicionantes del adulto corresponde a una regresión temporal, favorecida por el juego y el humor, a formas de conducta infantil o bufona ${ }^{10}$. Los adultos reconocen hacer, según dicen, "muchas chorradas", incluso peores que las que realizarían los niños, o cosas "nuevas" y "extrañas" que califican con expresiones tales como "hacer el indio". Las bromas comunes predominan, tales como las consistentes en hacer batallas de residuos de pan, aceitunas, cacahuetes, etc., o como las de inventar juegos imaginativos o producir sorpresas mediante petardos. Hay no obstante

\footnotetext{
${ }^{10}$ Este tipo de conducta -apologética de lo infantil, de la bufonería y de la locura- es típica en la fiesta carnavalesca (por ejemplo, Bajtin, 1987: 235).
} 
otros juegos más crudos, narrados por los falleros en las entrevistas. Algunos ejemplos son: visitar a alguien con una excusa a la hora de comer, y comerse toda la comida mientras se le distrae; llamar a las puertas de una Falla rival y escapar corriendo; explotar grandes petardos en lugares silenciosos; orinar sobre alguien desde lo alto de la escalera mientras se pone la decoración en las calles; disfrazarse y bromear con otras personas haciéndose pasar por una personalidad pública o ficticia, etc. Muchas de estas actividades, denominadas a veces "historias" o "aventuras", pueden resultar dificiles de creer para personas distanciadas del mundo festivo. Sin embargo, sus protagonistas son adultos muy respetables que actúan temporalmente como niños, y de un modo bufón, en una atmósfera de consentimiento mutuo. De esta manera se liberan, a través del juego y del humor festivos, de algún peso de "civilización". Por otra parte, los niños perciben esta nueva proximidad de los adultos. En una entrevista de grupo con niños, dos infantes narraron una disputa entre adultos y niños por la posesión de un juego de goma elástica de los niños. Concluyeron: "Ellos te dicen: ‘¿Puedo coger tu goma elástica?'. Y la cogen porque la quieren para jugar [Y cuando nos la cogieron no nos la querían devolver porque la querían para ellos]."

Después, los adultos desarrollan estrategias para reafirmar de nuevo su posición en relación con los niños, muchas veces respecto a sus propios hijos. En general, los niños comprenden estos vaivenes de la conducta de los adultos, pues su socialización en la fiesta es intensa y comienza muy temprano. No obstante, a veces fracasa el desarrollo de esta delicada transición hacia el rol anterior, y en ocasiones se impone una drástica solución de autoridad. Un fallero, que asumía "ser mucho peor que los niños" en la fiesta, narró el caso de un año en que su hijo se resistía a aceptar su vuelta a las rutinas formales de la relación padre-hijo al finalizar la fiesta. El padre, previamente un chistoso y bromista, señaló que "casi acabo encerrándolo en el maletero del coche".

En general, la sociabilidad festiva es terapéutica: la fiesta es phármakon. Los actores festivos se refieren constantemente a los efectos benéficos que tienen el juego y el humor. Algunos incluso ponen explícitamente en relación la sociabilidad con las artes. Un fallero señaló: "En la Falla ocurre lo mismo que con la música: te relajas, olvidas tus problemas, hablas, juegas con unos y con otros". En este sentido, los trabajos de Huizinga (1967) sobre el juego, así como los de Freud (1988) sobre el chiste y de Bergson (1986) sobre la risa, encuentran un buen test en la fiesta. Los participantes señalan los efectos liberadores que supone realizar cosas tales como jugar con petardos, disfrazarse, hacer bromas o contar chistes. Un fallero señaló: "Es importante darse cuenta de cómo la risa, toda esta expresividad, sirve para quitarse y poner fuera las cosas que tú piensas /.../, de este modo exteriorizas algo que estás reprimiendo". En la fiesta una parte más sustantiva de la persona sale a la luz, un ser más auténtico que, señala una fallera, "es como un niño". Esta misma fallera vinculó con la niñez las críticas 
realizadas durante la fiesta, en contraste con la formalidad exigida al adulto. La risa es muy importante en este proceso de apertura, y liberación, de la persona, un proceso que incluye un diálogo con la infancia:

Normalmente estás reprimida. Entonces esos días sale mi verdadero yo, la verdadera Julia, la verdadera fallera sale esos días: rompe con las cadenas, rompe con todas las cosas que la acompañan durante el año, cuando tienes que llevar tu máscara, de una persona formal, de una persona seria. Esos días tiras la máscara a un rincón, la tiras a un cajón. Entonces aparece tu verdadera persona, auténtica, que ríe, hace bromas y es más feliz que nunca /.../ El yo interior es siempre un niño pequeño, que tienes que reprimir porque la vida lentamente te hace un adulto. Esto significa que tú tienes que evitar ciertas cosas que años atrás estaban bien, pero ahora no. Se trata de críticas tontas, que no son de una persona adulta [su énfasis], y entonces ..."tú tienes que...", porque tú eres una persona adulta, y tienes más formalidad. Pero estos días rompes con la formalidad, y el verdadero ser de la persona aparece.

\section{CONCLUSIONES}

El análisis del ritmo de la sociabilidad festiva permite una investigación empírica detallada de la dimensión temporal de la Fiesta, tanto durante el periodo festivo como durante el resto del año, en el contexto de sus ciclos anuales. Como la sociabilidad está enraizada en la interacción generada entre los actores festivos concretos, el ritmo de la fiesta puede analizarse a partir de las variaciones en la dinámica de las secuencias, la intensidad y los contenidos de las actividades centrales de la sociabilidad festiva: el juego, el humor, el comensalismo y el trabajo sociable. La comunidad festiva realiza estas actividades de un modo permanente durante el periodo de preparación de la fiesta y las intensifica durante el evento festivo. Consiguientemente, el análisis del ritmo de la sociabilidad festiva nos permite hacer operativos para la investigación empírica los aspectos temporales (vinculados a la memoria colectiva) implicados en el concepto hermenéutico de "evento festivo".

Hemos observado que la memoria histórica y la identidad social de las Fallas, como comunidad y asociación, se generan y recrean a partir de los agentes (familia, grupos de amigos, vecinos) y actividades centrales de la sociabilidad festiva; es decir, a partir de la percepción subjetiva del tiempo festivo por parte de los actores que participan en la sociabilidad de la fiesta de las Fallas. Como he señalado, los participantes comprometidos tienen más tiempo festivo que los que participan poco y, además, la oposición predominante no se establece exactamente entre tiempo festivo (sagrado) y tiempo profano, sino entre el tiempo del disfrute de la sociabilidad festiva (tiempo festivo donde cabe el trabajo no remunerado para la fiesta) y el tiempo exigido por la jornada laboral que permite disponer de un salario. 
El ciclo anual de las Fallas presenta dos ritmos muy diferenciados en cuanto a la sociabilidad festiva: el largo tiempo de preparación ("durant tot l'any") y el periodo de la fiesta ("els dies de festa"). Durante los días de fiesta se produce una intensificación del ritmo y una expansión de la sociabilidad festiva, produciendo una transformación del sentido del tiempo y del espacio, que acentúa los "tiempos fundamentales" de la tradición y su mutua interacción. Estos tiempos fundamentales se expresan a través de las transformaciones personales y colectivas que experimentan los participantes en el contexto de esta intensificación de la sociabilidad festiva.

Los tres tiempos fundamentales de la fiesta están articulados. El tiempo biográfico supone, como el tiempo cíclico de la historia de la Falla para el colectivo, una vuelta periódica de apropiación de la experiencia, como un ejercicio de memoria. Los participantes "vuelven" a aspectos fundamentales de la persona que se encuentran en la niñez. Este proceso supone una "apropiación", tanto personal como colectiva, que acontece cuando se vive el tiempo "propio", ese tiempo lleno que exige demorar para retener lo propio (y singular) en lo transitorio y efimero. En esto, las Fallas son dignas herederas de la cultura europea de Carnaval, especialmente de su sátira contra las pretensiones e ilusiones de completud de la cultura oficial.

Estas características del tiempo en la fiesta son análogas a las del tiempo del arte, que en Heidegger (1995) se entiende también a partir del "evento de apropiación". Por otra parte, las afinidades que Simmel había establecido entre la forma de la sociabilidad y las del arte y el juego, se revelan también en su sentido del tiempo. De este modo, la fiesta (y el arte) evidencia que hay otros sentidos del tiempo, distintos al que presenta la preponderante comprensión tecnológica (y metafísica) del mundo, una comprensión que elabora nuevas "fantasías de completud" y pretende hacer del tiempo su instrumento principal de coordinación para la acumulación y el dominio.

\section{REFERENCIAS BIBLIOGRÁFICAS}

ARIÑO, A. (1992), La Ciudad Ritual. La Fiesta de las Fallas, Barcelona, Anthropos.

BAJTIN, M. (1987), La cultura popular en la Edad Media y en el Renacimiento, Madrid, Alianza Editorial.

BERGSON, H. (1986), La Risa, México, Porrúa.

COSTA, X. (1996), El lugar de la tradición en la sociología contemporánea, Tesis doctoral, Universidad de Valencia, Valencia.

(1998c), "Las Fallas de Valencia: el arte de la consagración del fuego", en M. Ángeles Durán (coord.), Arte y Sociedad, CIS, Consejo Superior de Investigaciones Cientificas, Madrid. 
(1999), Sociability and the Public Sphere in the Fallas of Valencia (unpublished PhD Thesis), University of Warwick, UK.

(2000), "El trabajo sociable en la Fiesta de las Fallas", Revista d' Estudis Fallers, $\mathrm{n}^{\circ}$ 5, pp. 25-37.

(2001a), "Festivity: Traditional and Modern forms of Sociability", Social Compass, International Review of Sociology of Religion, vol. 48, n 4, pp. 25-37.

(2001b), "Festive Identity", Association for the Sociology of Religion's Conference, Anaheim (USA), August.

DAVID, J. y A.J. WEIGERT (1992), "Estructura y significado del tiempo social", en R. Ramos (coord.), Tiempo y Sociedad, pp. 89-231, CIS, Madrid.

DURKHEIM, E. (1982), Las formas elementales de la vida religiosa, Akal, Madrid.

FRAZER, G. (1963), The Golden Bough, Londres, Macmillan.

FREUD, S. (1988), Freud. Obras Completas, Vol.V, Ensayo XXI-XXV, Barcelona, Orbis.

FUSTER, J. (1992), Combustible per a Falles, Alzira, Editorial Bromera.

GADAMER, H. (1991), La actualidad de lo bello, Barcelona, Paidós.

HEIDEGGER, M. (1982), Gesamtausgabe, n 52, Frankfurt am Main, Vittorio Klostermann.

(1994), "La pregunta por la técnica", Conferencias y artículos, Barcelona, Ediciones del Serbal.

(1995), "El origen de la obra de arte", Caminos de bosque, Alianza, Madrid.

HUIZINGA, J. (1972), Homo Ludens, Madrid, Alianza.

SANMARTÍN, R. (1996), "Cambio y tradición. Historia y modernización en la Comunidad Valenciana”, Revista de Antropología Social, $\mathrm{n}^{\circ}$ 5, pp. 125-162, Madrid.

SIMMEL, G. (1971[1910]), "Sociability", en Donald N. Levine (coord.), On individuality and social forms, Chicago, The University of Chicago Press, pp. 127-140. [Reimpresión de "The Sociology of Sociability", American Journal of Sociology, vol. 55, n³, 1949; traducido del original "Soziologie der Geselligkeit" (1910)]. 